\title{
A educomunicação no ensino profissional integrado ao médio: uma análise dos PPCS e Práticas Pedagógicas no campus Palmas do IFTO
}

\section{Educommunication in Vocational Education Integrated with High School: an analysis of PPCS and pedagogicals practices at IFTO campus Palmas}

Recebido: 30/07/2020 | Revisado: 23/11/2020 | Aceito: 28/11/2020 | Publicado: $01 / 03 / 2021$

Eliane Vieira de Ataides Valim

ORCID: https://orcid.org/0000-0002-53719380

Instituto Federal de Educação, Ciência e

Tecnologia de Tocantins

E-mail: elianevieiravalim@gmail.com

Mary Lúcia Gomes Silveira de Senna ORCID: https://orcid.org/0000-0002-4112 5470

Instituto Federal de Educação, Ciência e

Tecnologia de Tocantins

E-mail: marysenna@ifto.edu.br

\section{Rivadavia Porto Cavalcante}

ORCID: https://orcid.org/0000-0002-6568-

7910

Instituto Federal de Educação, Ciência e

Tecnologia de Tocantins

E-mail: riva@ifto.edu.br

\section{Weimar Castilho}

ORCID: http://orcid.org/0000-0002-56426049

Instituto Federal de Educação, Ciência e

Tecnologia de Tocantins

E-mail:weimar@ifto.edu.br

\section{Como citar:}

VALIM, E. V. A. et al,; A educomunicação no ensino profissional integrado ao médio: uma análise dos PPCS e Práticas Pedagógicas no campus Palmas do IFTO. Revista Brasileira da Educação Profissional e Tecnológica, [S.I.], v. 1, n. 20, p. 1-21, e10860, mar. 2021. ISSN 2447-1801.

This work is licensed under a Creative Commons Attribution 4.0 Unported License.

\section{Resumo}

Analisa a presença da educomunicação nas práticas pedagógicas no âmbito do Ensino Profissional Integrado ao Médio, tendo como lócus do estudo o Campus Palmas, do Instituto Federal do Tocantins (IFTO). Para tanto buscou-se por meio de pesquisa documental analisar os Projetos Pedagógicos de Curso (PPCs) e levantar dados das práticas docentes por meio de questionário. Utilizou-se ainda a pesquisa bibliográfica para conceituação e entendimento da educomunicação, buscando apontar sua importância para a formação ampla e integral. Na discussão e resultados o artigo aponta que embora o termo educomunicação não esteja presente nos PPCs, há um ideal educomunicativo nos projetos que permite seu implemento. As considerações finais destacam a necessidade do implemento da gestão da comunicação.

Palavras-chave: Educomunicação; Formação; Práticas Pedagógicas; Projeto Pedagógico de Curso; Ensino Profissional Integrado ao Médio.

\begin{abstract}
Analyzes the presence of educommunication in pedagogical practices implemented at Campus Palmas, the Federal Institute of Tocantins (IFTO), in the context of Professional Education Integrated to High School. To this end, it was sought through documentary research to analyze the Pedagogical Course Projects (PPC) and to collect data on teaching practices through a questionnaire. Bibliographic research was also used to conceptualize and understand educommunication, seeking to point out its importance for broad and comprehensive education. In the discussion and results the article points out that although the term educommunication is not present in the PPCs, there is an educommunicative ideal in the projects that allows its implementation. Final considerations point to the need to implement communication management.
\end{abstract}

Keywords: Educommunication; Formation; Pedagogical Practices; Pedagogical Course Project; Professional Teaching Integrated to High School. 


\section{INTRODUÇÃO}

Perante a reconfiguração social e cultural que vivemos, capitaneada principalmente pelas novas Tecnologias da Informação e Comunicação (TICs), temos consequentemente instituídos novos referenciais culturais, econômicos, comunicacionais, dentre outros (MATTAR; AGUIAR, 2018). Neste contexto, a área da educação enfrenta o grande desafio de conformar-se aos novos tempos, que exigem uma (re) significação do ensinar. Uma transformação não apenas das práticas, mas do processo de ensino como um todo, conforme nos aponta Martín-Barbero.

A educação já não é concebível a partir de um modelo de comunicação escolar que se encontra ultrapassado tanto espacial como temporalmente por processos de formação correspondentes a uma era informacional, na qual a idade para aprender são todas, e o lugar para estudar pode ser qualquer um: uma fábrica, uma casa para idosos, uma empresa, um hospital, os grandes e pequenos meios e especialmente a internet. (MARTíN-BARBERO, 2014, p. 121).

É neste contexto de necessária transformação para a educação, que a Educomunicação apresenta-se como um caminho para a reconfiguração do processo de ensino, seja como área de inter-relação e/ou convergência entre a educação e a comunicação ou como práxis de uma educação participativa e popular, baseada na comunicação para emancipação das pessoas e transformação social.

Nesta direção, este artigo busca verificar a presença da educomunicação nas práticas pedagógicas implementadas no Ensino Profissional Integrado ao Médio, tendo em vista o ascendente desta modalidade de ensino para uma formação integral, ampla e unitária. No entendimento de que a formação só alcançará essa amplitude se for capaz de relacionar o saber com a realidade em que o estudante vive, a educomunicação pode ter um papel fundamental no processo devido a seu caráter integrador.

O estudo dá-se no âmbito do Campus Palmas, do Instituto Federal do Tocantins (IFTO), por meio da análise dos Projetos de Pedagógicos de Curso (PPCs), na tentativa de verificar se a educomunicação está presente nos mesmos, e a aplicação de questionário aos professores das disciplinas técnicas da unidade, para conhecer a percepção dos mesmos sobre a educomunicação e verificar se a comunicação encontra-se como eixo estratégico em suas práticas.

Além de sua introdução, o artigo está organizado em mais quatro seções, sendo a segunda voltada ao referencial teórico sobre o tema, a terceira destinada à metodologia utilizada no estudo, a quarta refere-se a discussão e resultados das análises e a quinta e última seção é destinada às considerações finais. 


\section{A EDUCOMUNICAÇÃO E A RECONFIGURACCÃO DO PROCESSO EDUCACIONAL NO ENSINO PROFISSIONAL INTEGRADO AO MÉDIO}

Desafia o sistema educacional o fato de que a relação das pessoas com o conhecimento transformou-se. Evidentemente que o avanço tecnológico das últimas décadas proporcionou novos tempos e formas de aprender e ensinar. Chevallard (2013) salienta que essa relação transforma-se mais exatamente com o passar do tempo didático, ou seja, com a constatação de que princípios, métodos e técnicas ficaram ultrapassados e precisam progredir.

Fato é que na contemporaneidade temos a difusão do conhecimento por canais diversos e deste modo, conforme Martín-Barbero (2000, p. 55) a escola não é mais o único lugar de legitimação do saber "[...] pois existe uma multiplicidade de saberes que circulam por outros canais, difusos e descentralizados. Essa diversificação e difusão do saber, fora da escola, é um dos desafios mais fortes que o mundo da comunicação apresenta ao sistema educacional". Neste contexto, a educomunicação apresenta-se como uma alternativa para se superar estes desafios.

Na conceituação de Citelli (2014, p. 10) a educomunicação é uma "área de reflexão, pesquisa e intervenção social, cujo objetivo é o de trabalhar na interface comunicação e educação [...]", que propõe "[...] novos modos de organizar, distribuir e receber o conhecimento e a informação". Para Soares $(2002$, p. 24) a educomunicação é "[...] o conjunto das ações inerentes ao planejamento, implementação e avaliação de processos, programas e produtos destinados a criar e a fortalecer ecossistemas comunicativos em espaços educativos [...]". O autor aponta ainda para a educomunicação como política pública sendo "[...] um excelente caminho para renovação das práticas sociais que objetivam ampliar as condições de expressão de todos os segmentos humanos, especialmente da infância e juventude" (SOARES, 2011, p. 15).

Precursor do termo educomunicador, Kaplún (1998) anuncia a perspectiva da educação participativa e popular (que hoje chamamos educomunicação), na qual a comunicação tem papel central, como propulsora para um processo de ensino transformador e indica que a educação deve ser capaz de ativar as potencialidades do indivíduo, sua autonomia, suscitando seu autoconhecimento "observação pessoal, confronto e troca, agrupamento de alternativas, raciocínio crítico, elaboração criativa" (KAPLÚN, 1998, p. 191, tradução nossa). O autor afirma também que nesta compreensão a comunicação não é apenas uma profissão ou meio de vida, mas um serviço à sociedade, tendo a educomunicação ou a comunicação educativa o foco no resultado formativo do ser humano, na consciência da realidade, no suscitar da reflexão, para um processo educativo que não apenas ensine, mas transforme e promova a emancipação.

Deste modo, a importância da comunicação para os processos educativos torna-se estratégica, uma vez do lugar de centralidade que ela ocupa na sociedade contemporânea, na qual "praticamente tudo o que nos circunda, incluindo aspectos materiais, emocionais e simbólicos, mantém algum nível de relação com os meios de comunicação, as linguagens e os discursos neles gerados" (CITELLI, 2014, p. 10).

Trazendo isto para a realidade do Ensino Profissional Integrado ao Médio apontado por Moura, Lima Filho e Silva (2015) como potencial gênese para uma formação integral, ampla e unitária, voltada para o diálogo com as transformações 
sociais e humanas, com o propósito de emancipar e "tornar íntegro, inteiro, o ser humano dividido pela divisão social do trabalho entre a ação de executar e a ação de pensar, dirigir ou planejar" (CIAVATTA, 2005, p. 2) - a presença da educomunicação para esta modalidade de ensino tem um papel estratégico e até fundamental.

Isto porque ao contextualizar o processo de aprendizagem e conectá-lo ao mundo que cerca o estudante, a educomunicação dá ao Ensino Médio um sopro de vida e permite que o sistema de ensino olhe para o jovem a partir da realidade em que ele vive (SOARES, 2011). Se, conforme nos aponta Paulo Freire (1985, p.46) "a educação é comunicação, é diálogo, na medida em que não é transferência de saber, mas um encontro de sujeitos interlocutores que buscam a significação do significado", a proposta educomunicativa apresenta-se como horizonte para a educação que tem como meta a emancipação e o protagonismo dos estudantes, que é o caso do Ensino Profissional Integrado ao Médio.

Vê-se portanto que o Ensino Profissional Integrado ao Médio, como promessa de reconfiguração do sistema de ensino e "uma condição necessária para se fazer a "travessia" para uma nova realidade" (FRIGOTTO, CIAVATTA E RAMOS, 2010, p. 43) em que se estabeleça uma formação ampla, integral e omnilateral para os jovens, só poderá torna-se verdadeiramente efetivo se também for educomunicativo, pois a conexão do ensino com a vida do estudante e ao mundo que o cerca é essencial conforme nos aponta Freire.

É preciso vê-lo, portanto, em sua interação com a realidade, que ele sente, percebe e sobre a qual exerce uma prática transformadora. É exatamente em suas relações dialéticas com a realidade que iremos discutir a educação como um processo de constante libertação do homem. Educação que, por isso mesmo, não aceitará nem o homem isolado do mundo - criando este em sua consciência - nem tampouco o mundo sem o homem - incapaz de transformá-lo. (FREIRE, 1985, p. 66).

Desta forma, a via educomunicativa desponta como caminho para "ampliar as condições de expressão da juventude como forma de engajá-las em seu próprio processo educativo [...]" (SOARES, 2011, p. 15), sendo capaz de proporcionar aos jovens a mentalidade crítica e questionadora anunciada por Martín-Barbero (2000), que é capaz de tirar as pessoas da inércia em que vivem e romper com padrões sociais, culturais e econômicos pré-estabelecidos.

\subsection{A EDUCOMUNICAÇÃO PARA ALÉM DOS INSTRUMENTOS}

Antes de prosseguir com esta análise é preciso esclarecer um pouco mais a fundo a proposta educomunicativa ou tentar apontar, como se diz popularmente, que "uma coisa é uma coisa e outra coisa é outra coisa". Segundo Martín-Barbero (2014, p. 17) há o costume, que o autor diz beirar uma "forte esquizofrenia", de se "confundir a comunicação com os meios e a educação com seus métodos e técnicas". Partindo desse pressuposto, é preciso compreender que a educomunicação não configura-se apenas na utilização de instrumentos de comunicação como recursos didáticos, mas 
na inserção da comunicação no processo educativo, do qual ela passa a ser parte fundamental.

Sobre o assunto, Soares (2011, p 18) afirma que na educomunicação "o que importa não é a ferramenta disponibilizada, mas o tipo de mediação que elas podem favorecer para ampliar os diálogos sociais e educativos". Kaplún (1998, p. 7; tradução nossa) conscientiza que "toda ação educativa, até aquilo que é realizado pessoalmente na sala de aula e sem o uso de meios, envolve um processo comunicativo". O autor enfatiza que os recursos instrumentais são importantes, mas:

[...] há questões mais importantes do que técnicas. Não porque não são necessárias. Para fazer um bom material didático - um vídeo, um impresso, um programa de rádio - o domínio das respectivas técnicas específicas é essencial. Mas somente elas não são suficiente. Antes é preciso conhecer os princípios de uma boa comunicação, e eles se aplicam a todas as mídias igualmente. (KAPLÚN, 1998, p. 7; tradução nossa).

Ao explicar que educomunicar vai além de utilizar as ferramentas de comunicação, Soares (2000, p. 20) defende que "a própria comunicação se converta no eixo vertebrador dos processos educativos: educar pela comunicação e não para a comunicação". Neste contexto a comunicação não é apenas objeto, é relação com a educação. Contudo, o autor reforça que esta inter-relação educomunicativa só pode ocorrer a partir da construção de um projeto pedagógico amplo, ou seja, de um planejamento que tenha a comunicação como fio condutor.

Deste modo, fica claro que o fato de apenas fazer uso de instrumentos da comunicação no processo de aprendizagem, o que muitas vezes ocorre de maneira improvisada ou complementativa durante as aulas, não culmina a promoção da educomunicação no âmbito escolar.

\section{METODOLOGIA}

Este estudo classifica-se como aplicado, uma vez de sua intenção de contribuir a partir dos dados obtidos para o implemento de soluções. A pesquisa é exploratória, conforme nos aponta Gil (2017), pois busca-se o aprofundamento sobre a temática da educomunicação e sua importância para o ensino na atualidade, como também contribuir para sua discussão e análise acadêmica.

A abordagem utilizada foi a quali-quantitativa, considerando conforme Fonseca (2002) que a abordagem qualitativa possibilita a compreensão aprofundada das relações sociais. Já a análise quantitativa segundo Marconi e Lakatos (2011, p. 290) "é a mais apropriada para apurar atitudes e responsabilidades [...]" e "deve representar um determinado universo, para que seus dados possam ser generalizados e projetados para aquele ambiente", o que desta forma possibilita o estabelecimento de padrões de comportamento por meio da estatística. A técnica de pesquisa foi a observação direta extensiva, que conforme Marconi e Lakatos (2013, p. 86), "[...] realiza-se por meio do questionário, do formulário, de medidas de opinião e atitudes e de técnicas mercadológicas". 
Foram utilizados como procedimentos a pesquisa bibliográfica e a pesquisa documental. A pesquisa bibliográfica foi realizada por meio do levantamento de referenciais teóricos ligados ao tema abordado. O estudo baseou-se nas contribuições de diversos estudiosos das áreas da Educomunicação e Educação, como Kaplún (1998), Soares (2000, 2002 e 2011) e Martín-Barbero (2014); da Pedagogia, como Freire (1985); da Aprendizagem, como Moreira (1999). Além de autores da corrente marxiana que tecem as bases conceituais para a Educação Profissional e Tecnológica, como Moura (2015), Frigotto (2010), Ramos (2010) e Ciavatta (2005), dentre outros.

A pesquisa documental foi realizada por meio de fontes primárias, documentos oficiais. Foram analisados os PPCs dos oito cursos do Ensino Profissional Integrado ao Médio do Campus Palmas/IFTO, que são os cursos de: Administração, Agrimensura, Agronegócio, Controle Ambiental, Eventos, Eletrotécnica, Informática para Internet e Mecatrônica. Como os PPCs não estavam atualizados e/ou disponíveis no portal da instituição (portal.ifto.edu.br/palmas), com exceção para o do curso de Controle Ambiental, os mesmos foram solicitados e disponibilizados pela Direção de Ensino da unidade.

A análise dos PPCs buscou revelar se a educomunicação está presente nos projetos pedagógicos ou se os mesmos apontam para a inter-relação entre a comunicação e a educação nos processos de planejamento das práticas de ensino. A análise dos PPCs considerou que "a análise documental busca identificar informações factuais nos documentos a partir de questões ou hipóteses de interesse" (CAULLEY apud LÜDKE e ANDRE, 1986, p. 38).

Para tanto, foram analisados os itens metodologia e objetivos dos PPCs, nos quais buscou-se identificar termos que remetessem ao implemento da comunicação no processo de ensino, ou convergência entre as áreas de comunicação e educação. Deste modo foi feita a busca nestes itens do documento pelos termos educomunicação e comunicação e/ou termos relacionados ou ainda instrumentos de educomunicação que poderiam identificar a inter-relação entre as áreas, tais como a dança, a música, o audiovisual, a rádio escola, a internet: redes sociais e os ambientes de aprendizagem interativos, as artes visuais e a fotografia, entre outros.

Os termos buscados foram definidos tendo como referência as experiência educomunicativas apontadas no livro "Educomunicação: reflexões e prática na educação", organizado pela professora e coordenadora do Grupo de Pesquisa em Tecnologias, Comunicação e Educação (GTECOM), da Universidade Federal de Uberlândia (UFU), Diva Silva (2017). Foi realizada ainda a busca pelos termos educomunicação e comunicação no inteiro teor dos PPCs para verificar se havia menção aos mesmos em outras partes dos projetos.

A população envolvida no estudo é formada por 70 professores das disciplinas técnicas da unidade. A motivação para a realização da pesquisa com os professores das disciplinas técnicas deve-se ao fato de ser a oferta de disciplinas técnicas o grande diferencial do Ensino Profissional Integrado ao Médio, ou seja, o que caracteriza esta modalidade de ensino. A população foi levantada por meio do horário de aulas da unidade. No total 32 professores responderam à pesquisa, o que corresponde a amostra de $45,7 \%$ da população. A partir destes números tem-se, conforme cálculo estatístico de amostragem, uma confiabilidade de $90 \%$ no estudo e uma margem de erro de $10,82 \%$. 
Para o levantamento de dados a respeito da presença da educomunicação nas práticas pedagógicas utilizadas nas disciplinas técnicas da unidade foi proposto aos professores um questionário, por meio da ferramenta Google Forms, disponível no endereço: https://forms.gle/3HtyGJxrTMMNwf2P8 (GOOGLE FORMS, 2020). O link para o questionário foi disponibilizado aos coordenadores dos cursos do Ensino Profissional Integrado ao Médio pelo e-mail institucional, com solicitação para que encaminhassem o mesmo aos professores das disciplinas técnicas solicitando a participação na pesquisa. O questionário (apêndice 1) foi composto por 12 perguntas relacionadas a utilização da comunicação e/ou da educomunicação no processo de ensino. As questões tinham como pretensão levantar os conhecimentos dos professores a respeito das áreas, sua utilização ou não em suas práticas e seu interesse a respeito.

Após as respostas ao questionário, os resultados foram disponibilizados em gráficos, conforme figuras em item posterior, que apontam por meio de porcentagem o padrão de comportamento do grupo pesquisado. A partir da análise dos documentos e das respostas ao questionário, buscou-se relacionar e confrontar os resultados no intuito de revelar se a educomunicação está presente nos PPCs e práticas docentes no âmbito do Campus Palmas, do IFTO.

\section{DISCUSSÃO E RESULTADOS}

\subsection{A EDUCOMUNICAÇÃO NOS PPCS}

A análise do PPC do curso de Eventos revelou o direcionamento do curso para utilização de "alternativas metodológicas inovadoras e dinâmicas" (IFTO, 2013, p. 6). O PPC não faz menção aos termos comunicação e educomunicação em seus objetivos. Dentre as estratégias pedagógicas elencadas na metodologia, o PPC aponta a utilização da música, vídeos e filmes no processo de ensino. A palavra comunicação esteve presente no PPC 54 vezes. Embora não mencione o termo educomunicação, o documento enfatiza que a metodologia deve conduzir o estudante a:

[...] uma aprendizagem significativa, com critérios de referência, dando ênfase à bagagem intelectual do discente e ao sentido de diversidade, propiciando aprendizagem pessoal através do tratamento dado à informação, da interação dos diferentes conteúdos em torno de problemas e/ou hipóteses que facilitem a construção de conhecimentos e na transformação das informações oriundas dos diferentes saberes curriculares em conhecimento próprio. (IFTO, 2013, p. 21).

O PPC do curso de Eletrotécnica destaca a conformidade com a LDB 9.394/96, que prevê no Ensino Médio "o aprimoramento do educando como pessoa humana, incluindo a formação ética, o desenvolvimento da autonomia intelectual e o pensamento crítico" $(2013$, p. 9). A metodologia presente no documento enfatiza 0 aprendizado participativo e contextualizado e aponta que "na prática educativa deve- 
se procurar, através dos conteúdos e dos métodos, respeitar os interesses dos alunos e da comunidade onde vivem e constroem suas experiências" (IFTO, 2013, p. 23). O PPC não traz o termo educomunicação, mas a comunicação é mencionada 48 vezes no texto, em grande parte nas competências que espera-se que o estudante desenvolva durante o curso, como por exemplo:

- compreender e usar os sistemas simbólicos das diferentes linguagens como meios de organização cognitiva da realidade pela constituição de significados, expressão, comunicação e informação;

- entender os princípios das tecnologias da comunicação e da informação, associá-las aos conhecimentos científicos, às linguagens que lhes dão suporte e aos problemas que se propõem solucionar;

- entender a natureza das tecnologias da informação como integração de diferentes meios de comunicação, linguagens e códigos, bem como a função integradora, que elas exercem na sua relação com as demais tecnologias;

- entender o impacto das tecnologias da comunicação e da informação na sua vida, nos processos de produção, no desenvolvimento do conhecimento e na vida social;

- aplicar as tecnologias da comunicação e da informação na escola, no trabalho e em outros contextos relevantes para sua vida. (IFTO, 2013, p. 11-12).

O PPC do curso de Agrimensura não apresenta em seus objetivos termos que remetam à inter-relação entre a educação e a comunicação, contudo o item metodologia destaca o "[...] objetivo possibilitar ao estudante um aprendizado autônomo, participativo, interdisciplinar e contextualizado [...]" (IFTO, 2013, p. 21). O documento aponta ainda para a utilização de formas ativas de ensino e aprendizagem e enfatiza o foco no "desenvolvimento da autonomia de educadores e educandos, contribuindo para que o estudante seja o sujeito de sua formação com a ajuda necessária do professor" (IFTO, 2013, p. 21). O termo educomunicação não foi encontrado na busca, mas a palavra comunicação foi mencionada 48 vezes no documento, na maior parte em referência às competências relacionadas a disciplinas do curso.

O PPC do curso de Mecatrônica destaca o caráter multidisciplinar do mesmo e indica como objetivo "formar profissionais, promovendo a construção de competências que contemplem habilidades, conhecimentos e comportamentos que atendam às demandas do setor produtivo e das relações sociais" (IFTO, 2013, p. 9). A metodologia aponta que "os programas devem ser planejados valorizando os referidos interesses, o aspecto cognitivo e o afetivo", e que "os conteúdos devem possibilitar aos alunos meios para uma aproximação de novos conhecimentos, experiências e vivências. Uma educação que seja o fio condutor, o problema, a idéiachave que possibilite aos alunos estabelecer correspondência com outros conhecimentos e com sua própria vida" (IFTO, 2013, p. 23-24). A palavra educomunicação não foi encontrada no documento. A busca pela palavra comunicação resultou em 64 registros, em sua maioria referentes às habilidades e competências como nos outros PPCs analisados. 
Diferentemente dos outros PPCs, o do curso de Controle Ambiental é do ano de 2017 e foi encontrado no portal da instituição. O documento destaca entre os objetivos "oportunizar ao educando uma formação ética e o desenvolvimento da autonomia intelectual e do pensamento crítico" (IFTO, 2017, p. 28). O PPC não faz referência ao termo educomunicação. A busca pelo termo comunicação resultou em 30 ocorrências, em sua maioria ligadas às competências e habilidades. Em relação à comunicação, a metodologia indica que:

A utilização das Tecnologias da Informação e Comunicação (TICs) poderá ocorrer de forma complementar para a Formação Geral e em até $20 \%$ (vinte por cento) da carga horária diária do curso para a Formação Profissional, desde que haja suporte tecnológico e seja garantido o atendimento por docentes e tutores. (IFTO, 2017, p. 62).

A partir da análise dos PPCs foi possível verificar que o termo educomunicação não está incluso nos projetos que devem fundamentar as práticas pedagógicas dos cursos do Ensino Profissional Integrado ao Médio do Campus Palmas, do IFTO. Apesar disto, foi possível destacar nos PPCs apontamentos e/ou ideias que vão ao encontro dos fundamentos da educomunicação, dentre eles a educação participativa, a formação para a autonomia do estudante, o desenvolvimento do pensamento crítico e a integração entre a escola e a vida.

Foi possível verificar ainda que alguns PPCs, apesar de objetivos diferentes por serem referentes a cursos diversos, repetem a mesma metodologia, como é caso dos cursos de Informática para Internet, Agronegócio e Administração. Houve grande ocorrência da palavra comunicação nos documentos, na maioria das vezes relacionada às competências e habilidades que espera-se que o estudante desenvolva, porém não identificou-se nos projetos a sugestão de instrumentos ou processos educomunicativos que poderiam contribuir para tal.

Chama atenção o PPC do curso de Eventos, que apontou a utilização de "alternativas metodológicas inovadoras e dinâmicas" indo ao encontro da proposta educomunicativa, contudo para que a educomunicação seja verdadeiramente parte efetiva do processo de ensino é preciso que ela esteja incluída no planejamento, para que sua utilização não acabe por ocorrer de forma improvisada e intempestiva.

Nesta direção, Soares $(2011$, p. 37) esclarece que "a educomunicação enquanto teia de relações (ecossistema) inclusivas, democráticas, midiáticas e criativas - não emerge espontaneamente num dado ambiente. Precisa ser construída intencionalmente." O autor revela ainda que "'existem obstáculos que têm de ser enfrentados e vencidos. O obstáculo maior é, na verdade, a resistência às mudanças nos processos de relacionamento no interior de boa parte dos ambientes educativos $[\ldots] "$.

No caso, demanda, sobretudo, uma pedagogia específica para sua própria disseminação: uma pedagogia de projetos voltada para a dialogicidade educomunicativa, em condições de prever formação teórica e prática para que as novas gerações tenham condições não apenas de ler criticamente o mundo dos meios de comunicação, mas, também, de promover as próprias formas de expressão a partir da tradição latino-americana, construindo espaços de cidadania pelo uso 
comunitário e participativo dos recursos da comunicação e da informação. (SOARES, 2011, p. 37).

Outro ponto importante da análise diz respeito ao PPC do curso de Controle ambiental que apontou a utilização das TICs de forma complementar em até $20 \%$ da carga horária diária do curso. Entende-se que a limitação da utilização de tecnologias no passado foi um caminho para não se perder o controle do processo de ensino, contudo na atual sociedade digital que vivemos esta direção não é mais plausível. Esta limitação acaba por gerar no processo de ensino uma separação entre a educação e a comunicação, entre o ensino e a vida do estudante, quando o que deveria ocorrer é o contrário.

É preciso superar esta visão de separação, como se "[...] os dois mundos - o da educação e o da comunicação - não se tocassem ou, quando muito, permanecessem no âmbito da didática (a comunicação como recurso esporadicamente usado pelo professor)" (SOARES, 2011, p. 51). É justamente neste sentido que a educomunicação propõe a inter-relação da educação com a comunicação no processo de ensino como um todo e não de forma a preencher um espaço entre um conteúdo e outro. O intuito é tornar o processo de ensino amplo e integrado com a vida, para produzir motivação, autonomia e o desenvolvimento do pensamento crítico.

\subsection{A EDUCOMUNICAÇÃO NAS PRÁTICAS}

Em busca de dados relacionados à educomunicação e às práticas docentes implementadas no Campus Palmas, do IFTO, foi encaminhado um questionário com 12 perguntas (apêndice 1) aos professores das disciplinas técnicas da unidade. Dos professores que responderam ao questionário, 100\% indicaram que são professores das disciplinas técnicas.

Ao serem questionados sobre a presença da comunicação em suas práticas, $90,6 \%$, conforme figura 1, respondeu que acha que a comunicação está presente. Outros $9,4 \%$ disse que acha que a comunicação talvez esteja presente. Nenhum dos professores participante disse que a comunicação não está presente em suas práticas. Os dados revelam assim que a maioria dos professores acredita que a comunicação faz parte de suas práticas, o que demonstra a importância da área para a educação. 
Figura 1: Gráfico respostas pergunta 2

\section{2 - Você acha que a comunicação está presente em suas práticas pedagógicas? \\ 32 respostas}

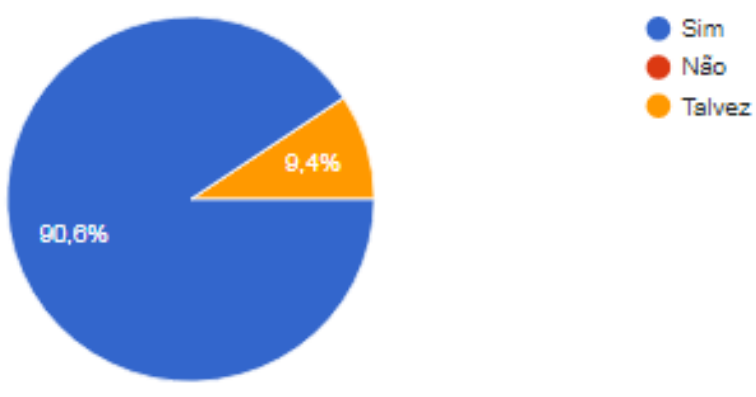

Fonte: Elaborado pelos autores

A terceira pergunta elencou uma série de opções de recursos e/ou materiais que podem servir como instrumentos de educomunicação, para verificar quais e com qual frequência eram utilizados pelos professores, que deveriam indicar se: as vezes utilizo, sempre utilizo ou nunca utilizei. As respostas resultaram no gráfico abaixo, que revela que nenhum dos participantes sempre utiliza músicas, programas de TV ou rádio como instrumentos pedagógicos. O gráfico revela ainda que a internet e sites já foram utilizados por todos, seja às vezes ou sempre. Revistas/jornais aparecem com alto índice de nunca utilizados. Já DVD/Filmes, fotografia, aplicativos e celular aparecem como às vezes utilizado.

Figura 2: Gráfico respostas pergunta 3

3 - Você utiliza ou já utilizou algum desses recursos ou materiais durante as suas aulas? Se você utiliza ou já utilizou algum, qual é a periodicidade? (Pode marcar mais de um)

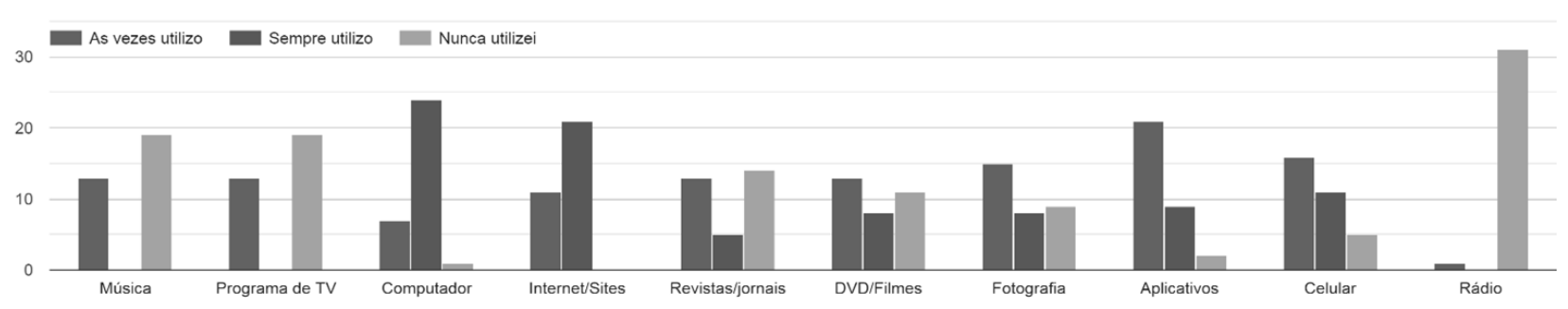

Fonte: Elaborado pelos autores

Deste modo as respostas, segundo a figura 2, apontaram que os menos utilizados são a música, os programas de TV e o rádio, o que demonstra que existe uma gama de possibilidades que podem colaborar com processos educomunicativos ainda a serem exploradas na unidade. Apesar do uso frequente da internet/sites, as revistas e jornais, que podem ser acessados atualmente pelos canais digitais, são pouco utilizados e poderiam ser mais explorados. A fotografia, aplicativos e celular, apesar de aparecem com maior índice de às vezes utilizados, podem ser instrumentos 
com grande potencial para o desenvolvimento de processos educomunicativos na unidade, uma vez que muitos professores também apontaram a sua utilização frequente.

Sobre o assunto, Soares (2011, p. 55) lembra que devido à "[...] inserção da tecnologia em sala de aula e da possibilidade de integrar ao currículo atividades que envolvam a participação dos jovens, diversas oportunidades são lançadas para que a comunicação, suas linguagens e tecnologias sejam incorporadas de fato como parte do processo educativo e pedagógico [...]". O autor adverte porém que "[...] o universo da comunicação representa, na contemporaneidade, um mundo de cultura que jamais poderia ser reduzido a um conjunto de ferramentas" (SOARES, 2011, p. 19).

Questionados sobre a utilização planejada dos instrumentos de comunicação, a maioria dos professores que responderam ao questionário, $71,9 \%$, quando utilizou algum recurso e/ou material ligado a área o fez de maneira não planejada, como mostra a figura 3. Já $28,1 \%$ apontaram que a utilização foi planejada conforme PPC do curso. É importante destacar sobre esta questão, que o planejamento é essencial para que a educomunicação aconteça de fato, uma vez que de acordo com Soares (2011, p. 37) a formação de um ecossistema educomunicativo "[...] exige clareza conceitual, planejamento, acompanhamento e avaliação". No âmbito escolar a importância do planejamento é ratificada em Padilha (2001, p. 63), que lembra que "[...] realizar planos e planejamentos educacionais e escolares significa exercer uma atividade engajada, intencional, científica, de caráter político e ideológico e isento de neutralidade".

Figura 3: Gráfico respostas pergunta 4
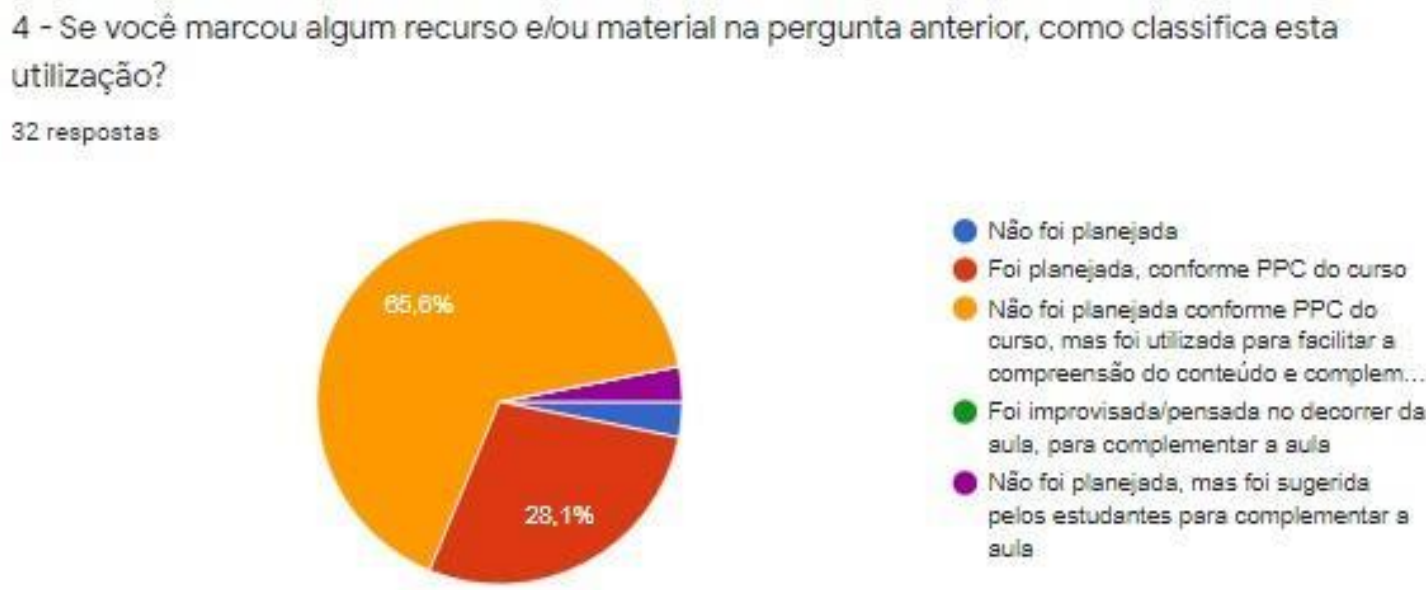

Fonte: Elaborado pelos autores

Perguntados se sabiam o que é educomunicação, 56,3\% dos professores responderam não saber, conforme a figura 4 . Já $37,5 \%$ disseram que sabiam e que trata-se de utilizar recursos da comunicação no processo de aprendizagem. Contudo, conforme destacou-se em seção anterior deste artigo à luz de Soares (2011) e Kaplún (1998), apenas a utilização dos recursos de comunicação no processo de ensino não configura a prática como educomunicativa. O que aponta que a maioria dos docentes que responderam não sabe o que é a educomunicação e grande parte dos que dizem saber estão equivocados a respeito. 
Figura 4: Gráfico respostas pergunta 5
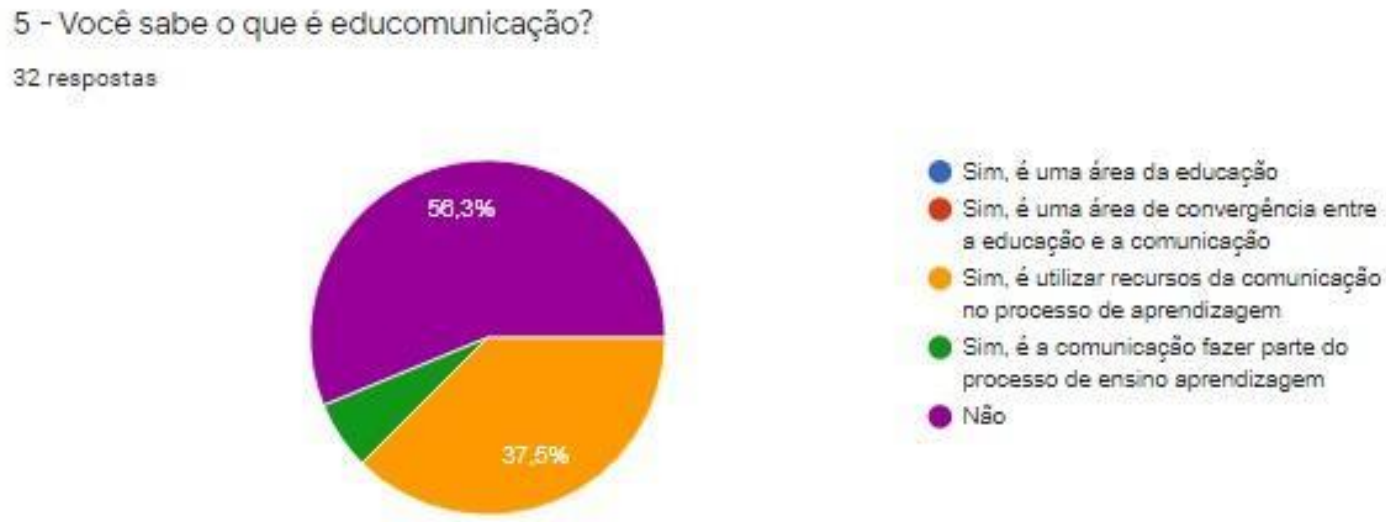

Fonte: Elaborado pelos autores

As perguntas 6, 7 e 8 (não obrigatórias) deveriam ser respondidas apenas por aqueles que disseram saber o que é educomunicação. Ao responderem se já haviam participado de algum curso de qualificação ou capacitação na área da comunicação, $75 \%$ responderam que não. Os outros $25 \%$ disse que sim. À pergunta 7 , que questionou se o professor se sente preparado para inserir/trabalhar com instrumentos de educomunicação, revelou que $62,5 \%$ não se sente preparado. Os outros 37,5\% disse que sente-se preparado. Os dados podem ser conferidos nas figuras 5,6 e 7 abaixo.

Deste modo as respostas revelaram que a maioria dos professores nunca participou de uma capacitação na área da comunicação e que a maioria não se sente preparado para inseri-la em suas práticas. As respostas evidenciam a carência de capacitações voltadas a esta área. Diante deste quadro é preciso ressaltar a necessidade de se criar espaços e oportunidades de capacitação na área da educomunicação aos docentes da unidade, para contribuir na formação de educadores que consigam "[...] dominar as linguagens produzidas socialmente na construção da cultura contemporânea", como propõe Soares (2011, p. 19).

Outro dado que merece destaque é a falta de projetos educomunicativos na unidade, uma vez que $93,8 \%$ disseram não conhecer ou participar de iniciativas voltadas à educomunicação. Apenas dois professores, 6,3\% do total, indicaram conhecer ou participar de algum projeto de educomunicação. Solicitados a apontarem o projeto responderam: "Nos projetos que atuo junto as comunidades tradicionais"; "Metodologias ativas".

A respeito do tema, Soares (2011, p. 49) destaca a importância de gestores e docentes esforçarem-se para implementar "[...] projetos comunicativos com especificidades próprias, que emprestem razões para o aluno gostar da formação recebida, criando nele o desejo de vê-la difundida e multiplicada". Para o autor "[...] a simples movimentação da estrutura de uma rede escolar ou de uma escola em direção aos parâmetros educomunicativos - através da pedagogia de projetos - já constitui um imenso progresso" (SOARES, 2011, p. 40). 
Revista Brasileira da Educação Profissional e Tecnológica, v. 1, n. 20, e10860, 2021, p. 14 de 20 (CC BY 4.0) | ISSN 2447-1801 | DOI: https://doi.org/10.15628/rbept.2021.10860

Figura 5: Gráfico respostas pergunta 6

6 - Você já fez algum curso de qualificação ou capacitação na área da comunicação?

16 respostas

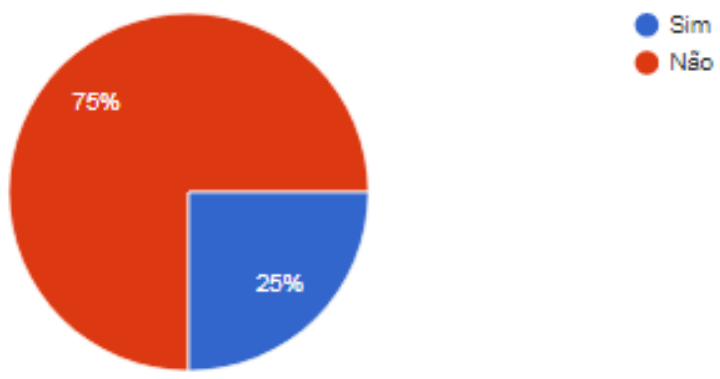

Fonte: Elaborado pelos autores

Figura 6: Gráfico respostas pergunta 7

6 - Você já fez algum curso de qualificação ou capacitação na área da comunicação?

16 respostas

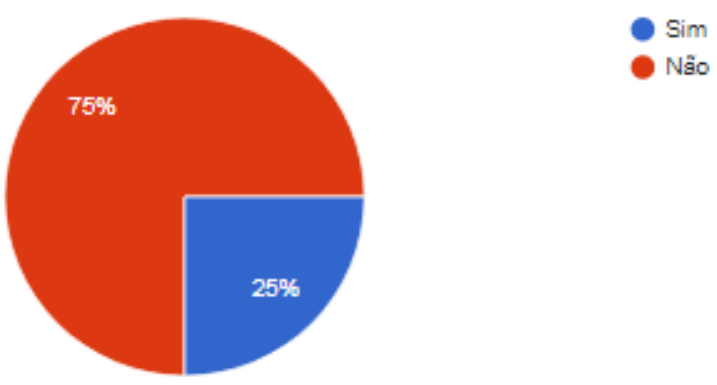

Fonte: Elaborado pelos autores

Figura 7: Gráfico respostas pergunta 8

8 - Você conhece ou participa de algum projeto de educomunicação no Campus Palmas/IFTO?

16 respostas

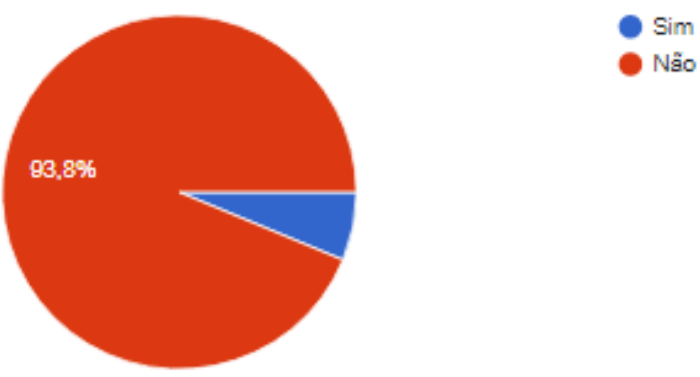

Fonte: Elaborado pelos autores 
A questão 9 solicitou a opinião dos professores sobre a utilização do celular na escola. Conforme a figura 8 , apenas $6,3 \%$ dos professores que responderam disseram que o celular não deve ser utilizado. A maioria, 93,8\% respondeu que acredita que a utilização do celular na escola pode contribuir ou ajudar. A décima questão também abordou o uso do celular, questionando os recursos já utilizados pelos professores. Ao responderem $62,5 \%$ responderam já ter utilizado o WhatsApp para auxílio de suas práticas, como mostra a figura 9. O Classroom foi utilizado por $18,8 \%$ e Hangout por $6,3 \%$. Os demais professores, $12,5 \%$ apontaram a utilização de outros recursos do celular como auxiliares em suas práticas.

Figura 8: Gráfico respostas pergunta 9
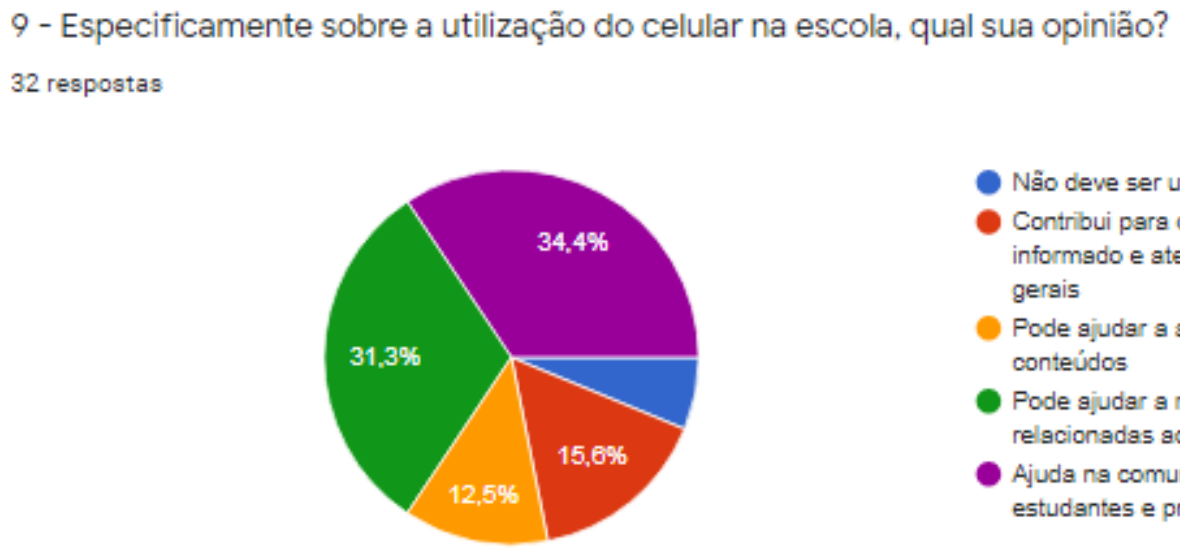

Não deve ser utilizado

Contribui para que o estudante esteja informado e atento às informaçốes gerais

Pode ajudar a aprender e fixar conteúdos

Pode ajudar a realizar pesquisas relacionadas aos conteúdos

- Ajuda na comunicação entre os estudantes e professores

Fonte: Elaborado pelos autores

Figura 9: Gráfico respostas pergunta 10

10 - Você já utilizou algum desses recursos pelo celular para o auxilio de suas práticas pedagógicas?

32 respostas
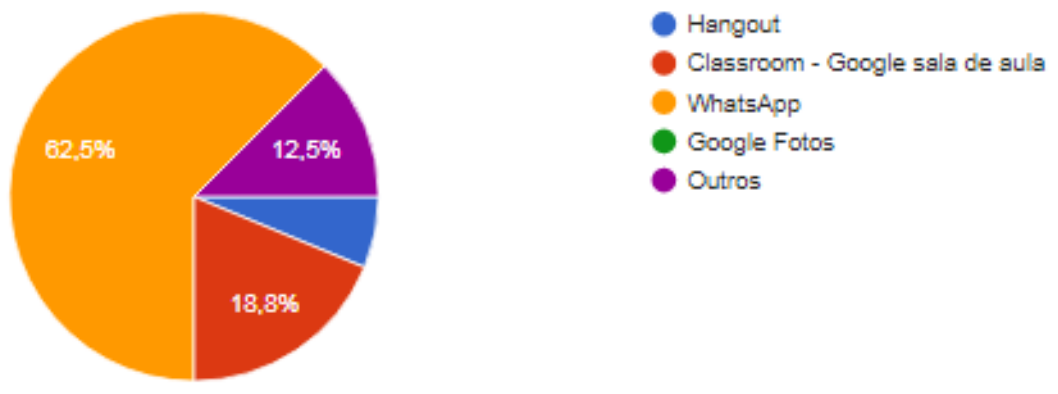

Fonte: Elaborado pelos autores

Deste modo, as respostas às questões 9 e 10 indicaram que a maioria dos professores que responderam ao questionário são a favor da utilização do celular na escola e que já utilizaram alguma ferramenta do mesmo, seja como canal de comunicação com os estudantes ou como instrumento voltado às atividades de 
aprendizagem. Este dado é importante, uma vez da popularização do celular na atualidade e principalmente entre os jovens.

Sobre essa percepção dos professores da unidade cabe ressaltar, consoante a Castells (2009, p. 378), a representatividade do celular para os jovens contemporâneos, que encontram neste aparelho "um instrumento adequado para expressar a necessidade de "autonomia segura", conectividade onipresente e redes autogerenciadas de práticas sociais [...] a comunicação móvel penetrou em todas as atividades e experiências da sociedade". Sendo assim, se utilizado de maneira planejada e educomunicativa, este instrumento pode colaborar com o processo de ensino, uma vez das diversas possibilidades que possui, que vão desde a pesquisa pela internet às atividades integradoras por meio de ferramentas e aplicativos, que permitem a captação e edição de sons e imagens.

Quando questionados na pergunta 11, se achavam que instrumentos de comunicação poderiam contribuir com suas práticas pedagógicas e se gostariam de utilizar alguns destes recursos, conforme a figura 10 abaixo, 90,6\% dos que responderam ao questionário disseram que sim, sendo que $40,6 \%$ disseram precisar de capacitação e $12,5 \%$ condicionaram a utilização a previsão no PPC do curso. Apenas $9,4 \%$ disseram que não gostariam de utilizar os recursos. Deste modo, a maioria dos professores acredita que instrumentos de comunicação podem contribuir com suas práticas, ajudar a ensinar e tornar a aprendizagem mais atraente.

Importante destacar que um número grande de professores reconheceu precisar de capacitação, o que demonstra a disposição e entendimento dos mesmos sobre a necessidade da capacitação docente na área da educomunicação. Neste sentido, Soares (2011, p. 20) lembra que "a proposta educomunicativa é facultar ao sujeito educador que se transforme, sem receios e com desenvoltura, em sujeito educomunicador. Torna-se necessário, pois, que sejam adotadas políticas que facilitem a formação desse novo docente-educomunicador".

Outro importante dado é o número considerável de professores que respondeu que é preciso que a comunicação esteja prevista no PPC, o que aponta mais uma vez a necessidade de que o projeto pedagógico aponte para a inter-relação entre a educação e a comunicação.

Figura 10: Gráfico respostas pergunta 11

11 - Você acha que instrumentos de comunicação, como por exemplo: música, fotografia, filmes, rádio podem contribuir com suas práticas pedagógicas? Você gostaria de utilizar algum desses recursos em suas aulas?

32 respostas

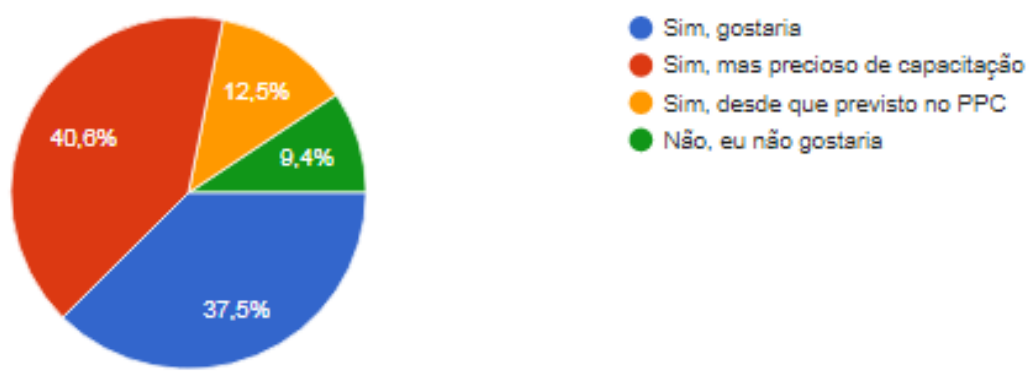

Fonte: Elaborado pelos autores 
A última questão perguntou aos que responderam sim à questão anterior, o que motivou a resposta. Conforme figura a seguir $41,4 \%$ acha que utilizar tecnologias de comunicação pode ajudar a ensinar, $31 \%$ acredita que o conteúdo ficaria mais atraente utilizando os instrumentos, $17,2 \%$ acham que seria uma oportunidade de aprender de uma forma diferente e $10,3 \%$ apontou que o desejo de utilizar os instrumentos de comunicação deve-se ao fato de gostar de música, fotografia, filmes, rádio, etc.

Claro que, como já dito neste texto, a prática educomunicativa não resume-se à utilização de instrumentos de comunicação, mas estas ferramentas segundo Soares (2011, p. 45) auxiliam para sua efetivação "como metodologia de ensino, aprendizagem e convivência", que se legitima pelo diálogo, por uma relação dialógica, que "[...] não é dada pela tecnologia adotada, mais ou menos amigável, mas essencialmente pela opção por um tipo de convívio humano. Trata-se de uma decisão ético-político-pedagógica, que necessita, naturalmente, ser circundada pela definição de tecnologias de auxílio".

Figura 11: Gráfico respostas pergunta 12
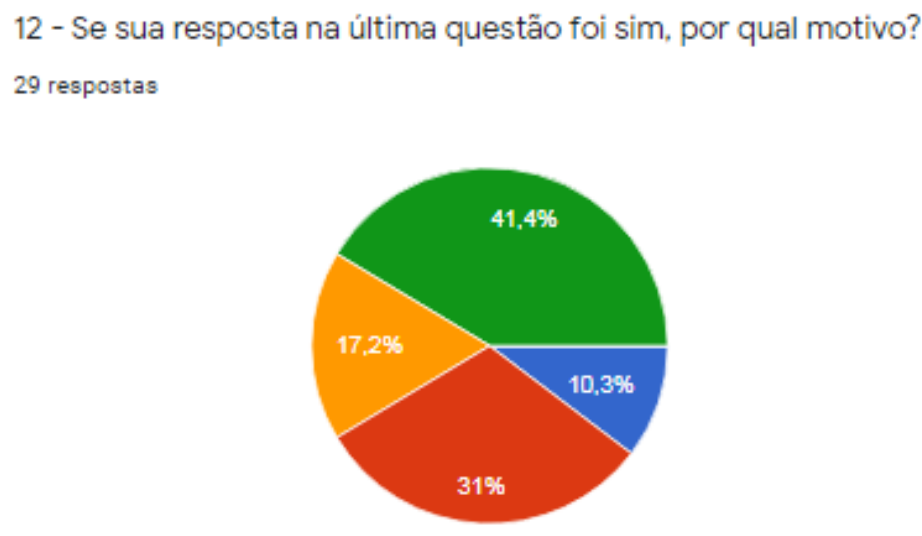

Gosto de músics, fotografis, filmes, rádio, etc.

O conteúdo ficaria mais atraente

Seria uma oportunidade de aprender de uma forma diferente

- Utilizar as tecnologias pode me ajudar a ensinar

Não tenho um motivo

Fonte: Elaborado pelos autores

\section{CONSIDERAÇÕES FINAIS}

A análise dos PPCs e dos dados gerados pelas respostas dos professores ao questionário permitiu vislumbrar a possibilidade de desenvolvimento e fortalecimento de práticas educomunicativas no âmbito do Campus Palmas, do IFTO.

Ao analisar os textos dos PPCs foi possível identificar trechos que vão ao encontro do ideal educomunicativo de emancipação, motivação e incentivo ao pensamento crítico do estudante, o que sem dúvida torna possível a inclusão efetiva da comunicação no processo de planejamento pedagógico da unidade. As respostas dos professores demonstraram ainda interesse sobre a área e a necessidade de capacitação.

Sendo assim, há a possibilidade e oportunidade para construção de um ecossistema comunicativo na unidade, contudo é preciso o entendimento de que a 
comunicação deve ser parte integrante do processo de ensino e não apenas um complemento limitado e aleatório. Sendo deste modo imprescindível a compreensão de que a educomunicação precisa ser construída por meio de ações eficazes e intenções coerentes a sua essência.

Nesta direção, é indispensável instituir uma política voltada a planejar e executar ações e projetos educomunicativos, uma "área da gestão da comunicação" na definição de Soares (2011, p. 48). Sobre o tema, o autor afirma inclusive que "o grande problema que ronda o Ensino Médio é o da gestão da comunicação em seus diferentes espaços, impedindo ou dificultando algo de fundamental importância na sociedade contemporânea: a expressão, a autoestima e a criatividade" (SOARES, 2011, p 14).

Importante destacar que esta pesquisa deu-se no momento em que os PPCs da unidade estavam sendo rediscutidos, ou seja, no momento propício para uma mudança/progresso dos processos e procedimentos de ensino. Deste modo, as condições existem, mas como pode-se notar esta construção demanda mais do que apenas condições. Demanda um agir educomunicativo consciente e competente voltado para uma formação verdadeiramente ampla, integral e omnilateral.

\section{REFERÊNCIAS}

CASTELLS, Manuel; FERNÁNDEZ-ARDÈVOL, M.; QIU, J. L.; SEY, A.

Comunicación móvil y sociedad, una perspectiva global. Cambridge, MA: MIT, 2009.

CHEVALLARD, Yves. Sobre a teoria da transposição didática: algumas considerações introdutórias. Revista de Educação, Ciências e Matemática. V.3 n. 2 maio/ago 2013.

CIAVATTA, Maria. A Formação Integrada: a escola e o trabalho como lugares de memória e de identidade. Trabalho Necessário. Ano 3, número 3- 2005.

CITELLI, Adílson. Educar para a comunicação. Revista SescTV. № 92 - novembro, 2014. Disponível em:

https://www.sescsp.org.br/online/artigo/8461_EDUCAR+PARA+A+COMUNICACAO. Acesso em: 12/01/2020.

FONSECA, J. J. S. Metodologia da pesquisa científica. Fortaleza: UEC, 2002. Apostila. Disponível

em:http://197.249.65.74:8080/biblioteca/bitstream/123456789/716/1/Metodologia\%20 da\%20Pesquisa\%20Cientifica.pdf. Acesso em 01/10/2019.

FREIRE, Paulo. Extensão ou comunicação. 8. ed. Rio de Janeiro: Paz e Terra, 1985. Disponível em:

https://docs.google.com/file/d/0B17CBePMBxFWVXIDY1RnSTdvbk0/edit. Acesso em: 04/02/2020.

FRIGOTTO, Gaudêncio; CIAVATTA, Maria; RAMOS, Marise. A gênese do Decreto n. 5.154/2004: um debate no contexto controverso da democracia restrita. Concepções e mudanças no mundo do trabalho e o ensino médio Ensino Médio Integrado. In: Concepção e contradições. 2ª ed. São Paulo. Cortez 2010. 
GIL, Antônio Carlos. Como elaborar projetos de pesquisa. São Paulo: Atlas, 2017.

GOOGLE FORMS. Website. https://forms.google.com. 2020. Disponível em: https://forms.gle/3HtyGJxrTMMNwf2P8. Acesso em 10/02/20.

IFTO. Projeto Pedagógico do curso técnico em Administração Integrado ao Ensino Médio. Diretoria de Ensino do Campus Palmas, do IFTO. 2013.

IFTO. Projeto Pedagógico do curso técnico em Agrimensura Integrado ao Ensino Médio. Diretoria de Ensino do Campus Palmas, do IFTO. 2013.

IFTO. Projeto Pedagógico do curso técnico em Agronegócio Integrado ao Ensino Médio. Diretoria de Ensino do Campus Palmas, do IFTO. 2013.

IFTO. Projeto Pedagógico do curso técnico em Controle Ambiental Integrado ao Ensino Médio. 2017. Disponível em: http://portal.ifto.edu.br/palmas/campuspalmas/cursos-palmas/tecnicos/integrado-regular/tecnico-em-controle-ambiental . Acesso em: 15/04/2019.

IFTO. Projeto Pedagógico do curso técnico em Eletrotécnica Integrado ao Ensino Médio. Diretoria de Ensino do Campus Palmas, do IFTO. 2013.

IFTO. Projeto Pedagógico do curso técnico em Eventos Integrado ao Ensino Médio. Coordenação do curso técnico em Eventos Integrado ao Ensino Médio, do Campus Palmas, do IFTO. 2013.

IFTO. Projeto Pedagógico do curso técnico em Informática para Internet Integrado ao Ensino Médio. Diretoria de Ensino do Campus Palmas, do IFTO. 2013.

IFTO. Projeto Pedagógico do curso técnico em Mecatrônica Integrado ao Ensino Médio. Diretoria de Ensino do Campus Palmas, do IFTO. 2013.

KAPLÚN, Mário. Una pedagogía de la comunicación. Madrid: Ediciones de la Torre, 1998.

LÜDKE, Menga; ANDRÉ, Marli E.D.A. Capítulo 3: Métodos de coleta de dados: observação, entrevista e análise documental. In: Pesquisa em educação: Abordagens Qualitativas. São Paulo: EPU, 1986. Disponível em: https://edisciplinas.usp.br/pluginfile.php/4247151/mod resource/content/2/Lud And cap3.pdf. Acesso em: 03/03/2020.

MARCONI, Marina de Andrade; LAKATOS, Eva Maria. Metodologia científica: ciência e conhecimento científico, métodos científicos, teoria, hipóteses e variáveis, metodologia jurídica. São Paulo: Atlas, 2011.

MARCONI, Marina de Andrade; LAKATOS, Eva Maria. Técnicas de Pesquisa: planejamento e execução de pesquisas, amostragem e técnicas de pesquisa, elaboração, análise e interpretação de dados. São Paulo: Atlas, 2013.

MARTÍN-BARBERO, Jesús. Desafios culturais da Comunicação à Educação. Comunicação \& Educação. São Paulo, [18]:51 a 61, maio/ago. 2000. Disponível em: http://www.revistas.usp.br/comueduc/article/view/36920/39642. Acesso em: $10 / 12 / 2019$.

MARTíN-BARBERO, Jesús. A comunicação na educação. São Paulo: Contexto, 2014. 
MATTAR, João; AGUIAR, Andra Pisan Soares. Metodologias ativas:

Aprendizagem baseada em problemas, problematização e método do caso.

Brasilian Journal of Education. In: Technology and Society. Vol 11, n.3. 2018.

MOURA, Dante Henrique; FILHO, Domingos Leite Lima; SILVA, Mônica Ribeiro.

Politecnia e formação integrada: confrontos conceituais, projetos políticos e contradições históricas da educação brasileira. Revista Brasileira de Educação. v. 20, n. 63, out.-dez. 2015.

MOREIRA, Marco Antônio. Teorias de Aprendizagem. Capítulo 7: A teoria da mediação de Vygotsky; Capítulo 10: A teoria da aprendizagem significativa de Ausubel. São Paulo. Editora Pedagógica e Universitária LTDA - UPU., 1999.

PADILHA, P. R. Planejamento Dialógico: Como construir o projeto político pedagógico da escola. Capítulo 2: Concepções de Planejamento. São Paulo: Ed. Cortez, 2001.

RAMOS, Marise. Ensino médio integrado: ciência, trabalho e cultura na relação entre educação profissional e educação básica. In Educação Profissional e Tecnológica no Brasil Contemporâneo. Pg. 42 a 57. Porto Alegre. Artmed, 2010.

SILVA, Diva. A experiência da educomunicação no contexto da pós-graduação. In: Educomunicação: reflexões e práticas na educação - Uberlândia: Navegando Publicações, 2017.

SOARES, Ismar de Oliveira. Educomunicação: o conceito, o profissional, a aplicação: contribuições para a reforma do ensino médio. São Paulo: Paulinas, 2011.

SOARES, Ismar de Oliveira. Educomunicação: um campo de mediações.

Comunicação \& Educação. N. 19, p. 12-24, dec. 2000. Disponível em; http://criancaeconsumo.org.br/wp-content/uploads/2000/09/Educomunicacao-umcampo-de-mediacoes.pdf. Acesso em: 15 dezembro de 2019.

SOARES, Ismar de Oliveira. Gestão comunicativa e educação: caminhos da educomunicação. Comunicação \& Educação. São Paulo. Ano VIII, jan/abr. 2002, no 23. Disponível em:

https://edisciplinas.usp.br/pluginfile.php/4614999/mod resource/content/3/Soares\%2 0Gest\%C3\%A30\%20Comunicativa.pdf\# blank . Acesso em: 17 de dezembro de 2019.

SOARES, Ismar de Oliveira. Prof. Ismar Soares fala sobre a educomunicação como política pública. Portal Direitos da Criança. Ago. 2011. Entrevista concedida a Ciranda - agência da Rede ANDI Brasil no Paraná. Disponível em: https://www.direitosdacrianca.gov.br/em-pauta/2011/08/em-10-anoseducomunicacao-pode-ser-politica-publica-em-todos-os-municipios-afirma-ismarsoares. Acesso em 15 de dezembro de 2019. 